\title{
Sinusoidal Back-EMF of Vernier Permanent Magnet Machines
}

\author{
Dawei, Li and Ronghai Qu
}

\begin{abstract}
Sinusoidal back-EMF waveform of vernier Permanent Magnet (PM) machines is analyzed in this paper. An analytical expression of Electromotive Force (EMF) of electric machines including vernier machines is developed to analyze EMF harmonics, and the effect of vernier PM machine pole ratio, the ratio of number of rotor poles to stator poles, on the EMF waveform. Moreover, this paper represents several Finite Element Analysis (FEA) models to verify the analysis based on the proposed expression, and the effect of tooth width ratio, which is the ratio of tooth width to tooth pitch, on back-EMF of vernier PM machines, and optimal tooth width ratio is obtained and verified by FEA. Finally, this paper makes comparisons between EMF waveform of vernier PM machines and that of traditional PM machines from the point of view of analytical EMF expression.
\end{abstract}

Keywords: Vernier permanent magnet (VPM) machine, sinusoidal back EMF waveform.

\section{Introduction}

In recent years, low-speed, high torque density electric machines attract more and more attention, and it is mainly contributed to booming direct drive applications, such as wind power, electric propulsion and so on. As a topology with high torque density and simple structure, vernier Permanent Magnet (PM) machines are more and more popular in the past decade.

As we know, vernier type motors were first derived from reluctance motor topology [1]. [2] presented a design methodology of surface PM vernier machines, and named their unique work operation as 'magnetic gear effect'. The relationship between vernier PM machine and magnetic gear was given, and a detail explanation how to convert a magnetic gear to a vernier PM machine was also shown in [3]. [4] presented the analytical analysis of air-gap flux density distribution and analyzed the effect of working harmonic and other harmonics on torque and torque ripple. The flux weakening performance of a vernier PM machine was discussed in [5].

Based on the same vernier topology, many new structures were represented. Dual excitation PM vernier PM machines were presented in [6], and it said this structure can realize very high-torque at low-speed.[7] presented a new structure with stator auxiliary teeth, which made concentrate-winding vernier PM machines possible. Further, the comparison of torque density of dual-rotor, dual stator and single stator

* School of electrical \& electronic engineering, Huazhong University of Sci.\& Tech., China (ronghaiqu@ hust.edu.cn)

Received 24 October 2013; Accepted 1 December 2014
PM vernier PM machines was done in [8], and it said that the dual-rotor vernier PM machines has higher torque density than that of other vernier structures shown in [8].

Back-EMF waveform is a key performance for electric machines, which heavily affects performances of electric machines, such as torque ripple, vibration, noise and reliability [9][10]. Moreover, the distortion of back-EMF waveform heavily increases losses, which requires larger cool capacity, and reduces the efficiency. In order to improve performance of PM machines, machine designers adopt many methods to improve the back-EMF waveform [9], but all these methods are not free. The short-pitch and distributed winding are the most common methods to suppress high order harmonics in back-EMF waveform, and skewed slots or skewed poles cooperated with short-pitch, distributed winding is always a well-known method to suppress slot harmonics in back-EMF waveform. These methods can gain more sinusoidal back-EMF waveform, however, the torque capability of electric machines is reduced, and the skewed slot or skewed pole leads to the more complex structure and may introduce unbalanced axial magnetic force as well.

The sinusoidal EMF waveform for a veriner machine is almost costless. This paper reports that the sinusoidal backEMF waveform is the inherent characteristic of vernier PM machines, and the integrate-slot, full-pitch, concentrated winding vernier PM machines can have a sinusoidal backEMF waveform.

Moreover, so far the analysis have not been seen which does a detailed analysis of this phenomenon and gives the 
reason why vernier PM machine has sinusoidal back EMF waveform.

This paper will represent a detailed analysis of backEMF of vernier PM machines and the effect of pole ratio and tooth width ratio on the back EMF waveform. In section II, the operation principle of vernier PM machine is overviewed. Section III will present a detailed expression of back-EMF for PM machines including vernier PM machines. Section IV will give a back-EMF harmonics analysis based on the EMF expression built in the section III. Section V gives the optimizing proceeding of pole ratio and tooth width ratio of vernier PM machines, and several FEA models are employed to verify the analysis in foregoing sections. From the point of view of EMF harmonics analysis, Section $\mathrm{V}$ compares back-EMF waveform of Fractional-Slot Concentrated -Winding (FSCW) PM machine to that of vernier PM machines.

\section{Detailed Formats of Manuscript}

\subsection{Principle of Vernier PM Machine}

Vernier PM Machines, A vernier PM machine, as shown in Fig. 1, includes a stator and a rotor with magnets, which has the same structure with traditional PM machines. However, the number of the stator pole pairs $p_{s}$ and the rotor pole pairs $p_{r}$ are unequal for vernier PM machines. In order to produce steady torque, the number of the stator pole pairs, the rotor pole pairs and the

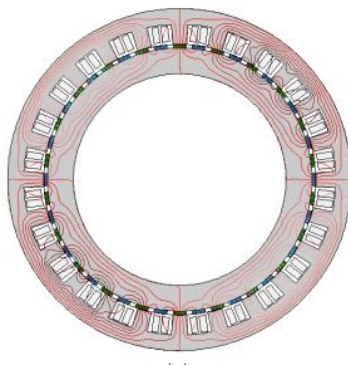

(a)

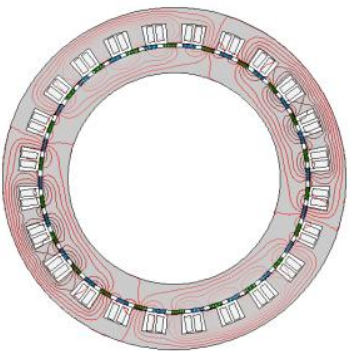

(b)
Fig. 1. The flux line of vernier PM machine at no-load (a) rotor position $=0$ omechnical angle (b) rotor position $=1.8$ omechnical angle

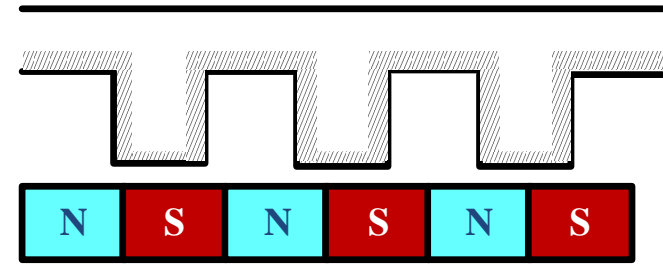

Fig. 2. The structure of vernier PM machine stator tooth of vernier PM machines should satisfy the following formula [10]:

$$
Z=p_{r} \pm p_{s}
$$

where $Z$ is the number of slots. As shown in Figure.1, the number of rotor pole pairs is 22 , and after the modulation effect of stator 24-slot, the number of pole pairs of flux density distribution in stator yoke is 2 . Fig. 1 shows that the rotation velocity of flux in stator yoke is 11 times higher than the rotor rotation velocity, while the flux per pole is determined by stator pole pairs $p_{s}$, so the amplitude of back-EMF of vernier PM machines are much larger than that of traditional PM machines, which leads to high torque density for vernier PM machines. However, since the rotor pole pitch and slot pitch are close, as shown in Fig. 2, the magnet-to-magnet flux leakage is large, so the power factor of vernier PM machines is relatively small compared with that of traditional PM machines.

\subsection{Analytical Expression of EMF of Vernier PM Machines}

For slotting PM machine, an equivalent slot-less machine is always employed to analyze performance of the slotting PM machine, such as torque and fundamental EMF amplitudes, by introducing Carter coefficient. However, this approach is unavailable in this paper, since the analysis of air-gap permeance harmonics introduced by slot is the subject to this paper.

This section will develop an analytical expression of back-EMF of PM machines including vernier PM machines, to qualitatively analyze EMF harmonics. Some assumptions are made before analysis:

- The machines discussed in this paper are three-phase;

- The number of coils per phase per pole $C P P=Z / 6 p s$ of vernier PM machines is an integer, where $p s$ is the number of stator pole pairs;

- The stator and rotor are unsaturated, i.e. the MMF drop in stator and rotor is neglected;

- The air-gap flux in axial and circumferential direction is neglected.

Approximate Distribution of Air-gap Flux Density Excited by Permanent Magnet

First of all, a cylindrical coordinate is placed on the stator inner surface, and the axis of phase $\mathrm{A}$ is selected as $\theta_{s}=0$. When $t=0$, the $d$ axis of PM rotor is aligned with axis of phase $\mathrm{A}$, and then the spatial distribution of MMF excited by the permanent magnet can be expanded into a Fourier series: 


$$
f_{m}\left(\theta_{s}, t\right)=\sum_{i=1,3,5 \ldots} F_{i} \sin \left(i \alpha \frac{\pi}{2}\right) \cos \left(i p_{r} \theta_{s}-i \omega t\right)
$$

where pis the number of pole pairs of permanent magnets, is the electrical velocity, and is the ratio of pole arc to pole pitch. If the Magnetic Motive Force (MMF) excited by permanent magnet is satisfied: $f_{m}\left(\theta_{r}\right)=f_{m}\left(-\theta_{r}\right)$ and $f_{m}\left(\theta_{r}\right)=-f_{m}\left(\theta_{r}+\pi / p\right)$, where $\theta_{r}=\theta_{s}-\omega t / p$ is the value in terms of reference frame built on the rotor, there are only odd harmonics of MMF's Fourier series, and it is always true for traditional PM machines. [2]:

The air-gap magnetic permeance can be represented by

$$
\Lambda=\Lambda_{0}+\sum_{k=1}^{\infty} \Lambda_{k}(-1)^{n} \sin \left(k \alpha_{t} \pi\right) \cos \left(k Z \theta_{s}\right)
$$

where a is tooth width ratio, and $\mathrm{n}$ is the number of slot shifts for short pitch, and in this paper $n$ is assumed as 0 , i.e. full-pitch winding.

In this paper, only the radial component of flux density in air-gap is considered, so the flux density can be represented by the formula:

$$
b_{m}\left(\theta_{s}, t\right)=f\left(\theta_{s}, t\right) \Lambda\left(\theta_{s}\right)
$$

Winding Function, In order to expediently analyze the EMF harmonics of a PM machine, winding function theory is employed [11], and the winding function can be represented by the a series of sinusoidal windings as shown below:

$$
N\left(\theta_{s}\right)=\sum_{j=1,3 \ldots} N_{j} k_{d q j} \cos \left(j p_{s} \theta_{s}\right)
$$

where $\mathrm{N}$ is the winding function of one phase armature winding, and $\mathrm{k}$ is the winding factor of $\mathrm{J}$ order harmonic, regardless of skew slot or pole factor. Thus the traditional distributed winding has only odd harmonic sinusoidal winding function component, due to the symmetric winding disposition. The special attention should be paid to the fraction slots concentrated winding topology, whose winding function should be represented as:

$$
N\left(\theta_{s}\right)=\sum_{j=1,2 \ldots} N_{j} k_{d q j} \cos \left(j \theta_{s}\right)
$$

EMF Expression, after analysis of air-gap flux density distribution, an EMF expression is obtained using the Faraday's law of induction:

$$
e=-\frac{d \psi_{m}}{d t}=-\frac{d}{d t} r l \int_{0}^{2 \pi} b_{m}\left(\theta_{s}, t\right) N\left(\theta_{s}\right) d \theta_{s}
$$

These equations shown below help simplify the EMF expression.

$$
\begin{aligned}
k_{d q i} \frac{p r}{p s} & =(-1)^{n} k_{d q i}, k_{d q \frac{i p r \pm k z}{p s}}=(-1)^{k+n} k_{d q \frac{i p r}{p s}}=(-1)^{k} k_{d q i} \\
k_{d q i \pm \frac{z}{p}} & =(-1)^{k+n} k_{d q i}
\end{aligned}
$$

Then the expression can be simplified as:

$$
\begin{aligned}
& e= \\
& \sum_{i=1,3,5, \ldots} r l w \pi \Lambda_{0} F_{1} N_{1} \frac{p_{s}}{p_{r}} \sin \left(i \alpha \frac{\pi}{2}\right) \frac{k_{d q i}}{i}(-1)^{n}\left[1+\sum_{k=1}^{\infty}(-1)^{k} \frac{\Lambda_{1}}{k \Lambda_{0}} \frac{1}{1-\left(\frac{k}{i} \frac{z}{p_{r}}\right)^{2}} \sin \left(k \alpha_{1} \frac{\pi}{2}\right)\right] \sin i \omega t \\
& (9)
\end{aligned}
$$

The expression shows that EMF consists of two components: the left one in brackets is induced by air-gap flux excited by interaction between PM MMF with constant permeance component, which is called slot-less component in this paper; the other one is induced by the flux caused by the PM MMF with air-gap permeance harmonics, which is named as slotting component in this paper.

For traditional PM machines, $p_{r}=p_{s}=p$, and $Z / p$ is always represented as $6 q$, where $q$ is the number of coils per phase per pole, and then the EMF expression of traditional PM machines is given by:

$$
\begin{aligned}
& e= \\
& \sum_{i=1,3,5, \ldots} r l w \pi \Lambda_{0} F_{1} N_{1} \sin \left(i \alpha \frac{\pi}{2}\right) \frac{k d q i}{i}(-1)^{n}\left[1+\sum_{k=1}^{\infty}(-1)^{k} \frac{\Lambda_{1}}{k \Lambda_{0}} \frac{1}{1-\left(\frac{k}{i} 6 q\right)^{2}} \sin \left(k \alpha_{t} \pi\right)\right] \sin i \omega t
\end{aligned}
$$

For vernier PM machines, $p_{r}>p_{s}$ is always true, and there is a unique factor $R_{p}$, the ratio of rotor pole number to stator pole number, for vernier PM machines and then the EMF expression of vernier PM machines can be obtained:

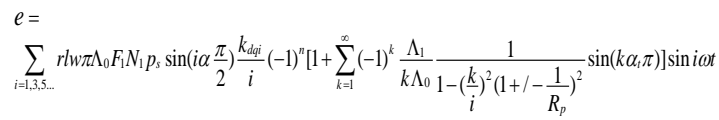

which is corresponded to vernier machines with $z=p_{r}+p_{s}$ and $z=p_{r}-p_{s}$ respectively.

This expression proves that a design with $z=p_{r}+p_{s}$ has higher torque density compared to a design with $z=p_{r}-p_{s}$ Since slot-less component and slotting component of working EMF harmonics of vernier PM machines with $z=p_{r}+p_{s}$ are in phase, and that of vernier PM machines 
with $z=p_{r}-p_{s}$ are in opposition. This paper focuses on the case of $z=p_{r}+p_{s}$, which has larger torque density.

\subsection{Analysis of EMF Harmonics}

In order to expediently analyze the relationship between $i$ order EMF harmonic with working harmonic, the EMF amplitude expression is simplified as:

$$
\begin{aligned}
E_{i} & =E_{\text {sloteless }-i}+\sum_{k=1,3,5 \ldots} E_{\text {slotting }-i, k} \\
E_{i} & \propto \frac{k_{d q i}}{i} \sin \left(i \alpha \frac{\pi}{2}\right)\left[1+\sum_{k=1,3,5 \ldots}(-1)^{k} \frac{\Lambda_{1}}{k \Lambda_{0}} \frac{1}{1-\left(\frac{k}{i} \frac{z}{p_{r}}\right)^{2}} \sin \left(k \alpha_{t} \pi\right)\right]
\end{aligned}
$$

where $E_{\text {slotess }-i}$ is the slot-less component of EMF harmonics and $E_{\text {slotting-i,k }}$ is the slotting component induced by interaction between $k$-order permeance harmonic and ${ }^{i}$-order MMF harmonic. Moreover, the calculation models in following sections are 11-pole ratio, 0.5-tooth width ratio vernier machines with full pitch winding.

EMF of Traditional PM Machines for traditional PM machines, the number of slot per pole per phase ${ }^{q}$ is a positive integer, so the amplitude of the slotting component of $i \neq k Z / P \pm 1$ order harmonics, which is called belt harmonics, is much smaller than that of its slot-less component as shown in Fig. 3(a), and then the ratio of amplitude of the low order EMF harmonics to that of working harmonic can be simplified as:

$$
\frac{E_{i}}{E_{1}} \approx \frac{E_{\text {slotless }-i}}{E_{\text {slotless }-1}}=\frac{k_{d q i}}{i k_{d q 1}}
$$

The harmonics with ${ }^{i=k Z / P \pm 1}$, where ${ }^{k=1,2,3 \ldots}$, are always called slot harmonics. For an integer-winding configuration, the value of $k Z / P \pm 1$ is always large, e.g. when $\mathrm{q}=2$ and $\mathrm{k}=2, k Z / P \pm 1$ is 23 or 25 , which leads to a low amplitude of corresponding winding function harmonics, so only $Z / P \pm 1$ th order EMF slot harmonic is taken into account for traditional PM machines, i.e. regardless of large order permeance harmonics' effect on EMF harmonics. As well known, the winding factor of slot harmonics is same as that of working harmonic. Moreover, if the harmonic order ${ }^{i}$ is $Z / P \pm 1$, the amplitude of $1 /\left(1-\left(Z / p_{r}\right)^{2}\right)$ is quite large as shown in (1). In other word, stator slots enlarge the amplitude of EMF slot harmonics. The amplitude of slot harmonics slotting component is much larger than that of slot-less component for PM machine with open-slot configuration, as shown in Fig. 2(b)

$$
\frac{E_{i}}{E_{1}} \approx \frac{E_{\text {slotting }-i}}{E_{\text {slotess }-1}}=\frac{1}{i} \frac{\Lambda_{1}}{\Lambda_{0}} \frac{1}{1-(6 q)^{2}} \sin \left(\alpha_{t} \frac{\pi}{2}\right)
$$

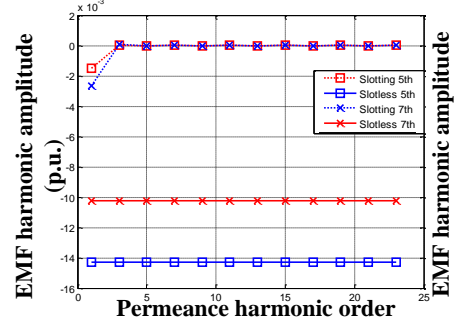

(a)

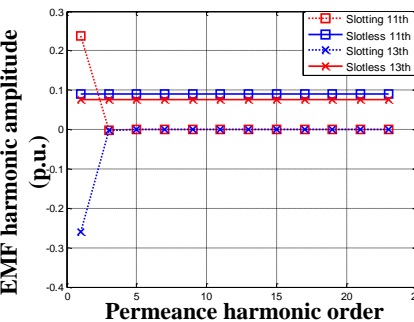

(b)
Fig. 3. Variation of traditional PM machines EMF and for a harmonics slot-less component and slotting component with permeance harmonic (a) 5 th 7 th EMF harmonics (b) 11th 13th EMF harmonics

EMF of Vernier PM Machines Since the number of slots and rotor pole pairs of vernier PM machines are close, the value of $k z / p_{r} \pm 1$ is small in an integer winding configuration, so the high order permeance harmonics should be considered, e.g. $k z / p_{r} \pm 1=\frac{12}{11} k \pm 1$, 44-rotor pole, 24-slot, and 4-stator pole vernier machine.

$$
E_{i} \propto \frac{k_{d q i}}{i} \sin \left(i \alpha \frac{\pi}{2}\right)\left[1+\sum_{k=1,3,5, \ldots}(-1)^{k} \frac{\Lambda_{1}}{k \Lambda_{0}} \frac{1}{1-\left(\frac{k}{i}\right)^{2}\left(1+\frac{1}{R p}\right)^{2}} \sin \left(k \alpha_{t} \pi\right)\right]
$$

The amplitude of slotting component of EMF working harmonic of vernier PM machines is larger than that of slotless component, while the amplitude of slotting components of other EMF harmonics are close to that of slot-less component, as shown in Fig. 4, rather than much smaller in traditional PM machines.

The amplitude of slotting component of EMF harmonic of vernier PM machines and that of slot-less component are approximately equal, in order to simplify the expression further, $\alpha$ and $\alpha_{t}$ are assumed to be 2/3and 0.5 respectively, and then the ratio of amplitude of $i$-order EMF harmonic to that of working harmonic is given by:

$$
\frac{E_{i}}{E_{1}}=\frac{E_{\text {slotess }-i}+E_{\text {slotting }-i, i}+\sum_{k \neq i} E_{\text {slotting- } i, k}}{E_{1}}
$$

where $E_{\text {slotting-i,k }}$ is the component of EMF harmonics caused by the interaction between $i$ order rotor MMF harmonic and $k$ order permeance harmonic. 

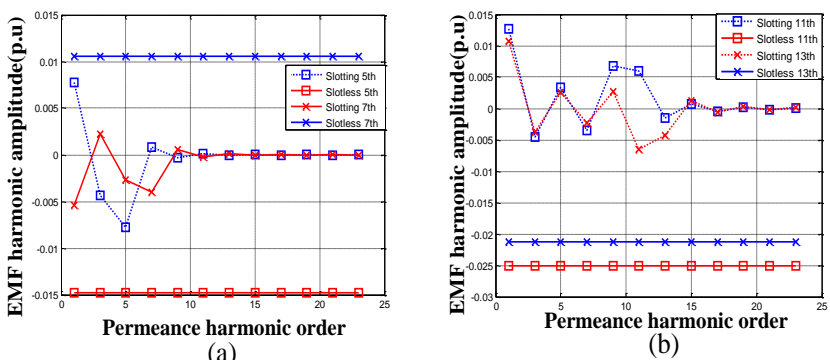

(a)

Fig. 4. Variation of 11-pole-ratio vernier PM machines EMF harmonics slot-less component and slotting component with permeance harmonic (a) 5th 7th EMF harmonics (b) 11th 13th EMF harmonics

For the slot-less component of $i$ order EMF harmonic,

$$
\frac{\left|E_{\text {slotless }-i}\right|}{\left|E_{1}\right|}=\left|\frac{k_{d q i}}{i k_{d q 1}} /\left[1-\frac{\Lambda_{1}}{\Lambda_{0}} \frac{1}{1-\left(1+\frac{1}{R p}\right)^{2}}\right]\right|<<\left|\frac{k_{d q i}}{i k_{d q 1}}\right|
$$

For slotting component of $i$ order EMF harmonic, the analysis is more complex than slot-less component of EMF harmonic, since the high order permeance harmonics should be taken into account. If $k \neq i$,

$$
\frac{\left|E_{\text {slotting }-i, k}\right|}{\left|E_{1}\right|} \approx\left|\frac{k_{d q i}}{i k_{d q 1}} \frac{\Lambda_{1}}{k \Lambda_{0}} /\left[1-\frac{\Lambda_{1}}{\Lambda_{0}} \frac{1}{1-\left(1+\frac{1}{R p}\right)^{2}}\right]\right|<<\left|\frac{k_{d q i}}{i k_{d q 1} \mid}\right|
$$

while it should be noticed that $E_{\text {slotting-i,k }}$ and $E_{\text {slotting }-i, k-2}$ are in opposition, as shown in Fig.4. If $k=i$, $\frac{\left|E_{\text {slotting-i,i }}\right|}{\left|E_{1}\right|}=\frac{1}{i}\left|\frac{k_{d q i}}{i k_{d q 1}} \frac{\Lambda_{1}}{\Lambda_{0}} \frac{\sin \left(k \alpha_{t} \pi\right)}{\sin \left(\alpha_{t} \pi\right)}\right|$ ,and it shows that the amplitude of slotting component of EMF harmonics, which satisfies $k=i$, heavily reduces as the number of harmonics order $i$ increases.

Moreover, the first order slotting component of ${ }^{i}$-order EMF harmonic $E_{\text {slotting-i,1 }}$ and the slot-less component $E_{\text {slotess }-i}$ are in opposition, as shown in Fig. 4, so $E_{i} / E_{1}$ of vernier machines is small, i.e. vernier PM machines have sinusoidal EMF waveform.

\subsection{Optimization of pole ratio and tooth width ratio}

In this section, the analytical EMF expression and several FEA models are employed to analyze the effect of different pole ratio, and tooth width ratio on EMF waveform, while table I lists the FEA models parameters. It should be noticed that all of the FEA models have 120 o pole arc, and same ratio of pole pitch to air-gap length.
Since the number of stator poles, slots and rotor poles satisfy(1), vernier PM machine pole ratio $p_{r} / p_{s}=(6 q-1)=5,11,17 \ldots \quad$. The Total Harmonic Distortion (THD) of EMF reduces as the pole ratio increases when tooth

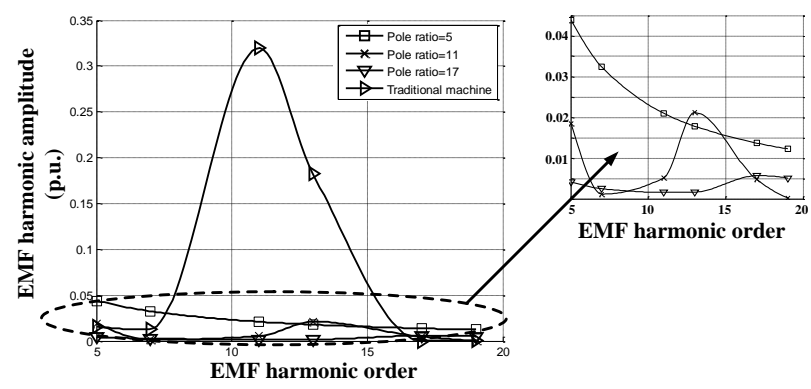

Fig. 5. Calculation result of amplitude of EMF harmonics of 24-slots 4-pole PM machines, and vernier PM machine with 0.5 -tooth width ratio

width ratio is 0.5 as shown in Fig. 5, and it is verified by the FEA result as shown in Fig.6. It should be noticed that this analytical expression is used to qualitatively analyze EMF harmonics of PM machines with different topologies, and it is difficult to use the expression built in this paper to accurately optimize tooth width ratio, and FEA is employed to analyze the effect of tooth width ratio on the back-EMF waveform.
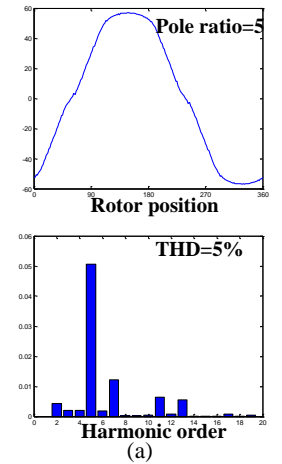
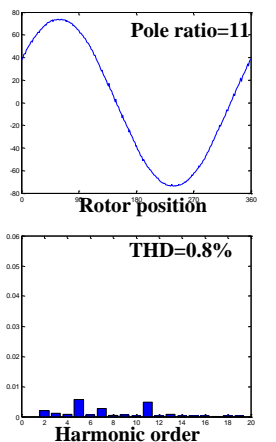

(b)
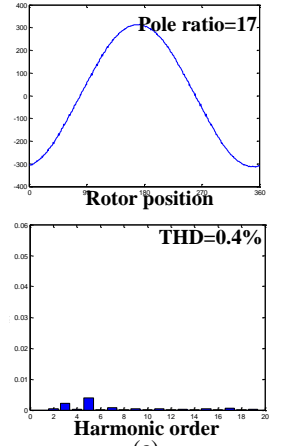

(c)
Fig. 6. Variation of EMF harmonics of vernier PM machine with pole ratio,(a) pole ratio $=5$,(b) pole ratio $=11$,(c) pole ratio $=17$

Compared to tradtional PM machines, since the EMF working harmonic of vernier PM machines is determined by its slotting component, tooth width ratio heavily influence the performance of vernier PM machines. Fig.7 shows that comparison among the THD of back EMF of vernier PM machines with 5- pole ratio, 11-pole ratio and17-pole ratio, and it shows that the tooth width ratio heavily affects the THD of back EMF. When tooth width ratio is 0.45 , the THD of 5-pole ratio vernier PM machine is lowest, and the amplitude of fundamental back EMF is 
highest, while the highest amplitude of vernier PM machine with 11-pole ratio and 17-pole ratio can be obtained when tooth width ratio is 0.4 .

It should be noticed that back EMF waveform THD of the vernier PM machine with 17 pole ratio and 0.4 tooth width ratio is higher than that of 17-pole-ratio vernier machine with other tooth width ratio, however, the THD of the design with17 pole ratio and 0.4 tooth width is still below $1 \%$, so 0.4 tooth width ratio is preferred for the design of vernier PM machines with 11 pole ratio and 17 pole ratio. For vernier PM machines with 5 pole ratio, the design with 0.45 tooth width ratio is preferred, due to lowest THD of back EMF waveform and high amplitude of working back EMF harmonic.

This optimization design can be explained by the FEA result of flux density distribution in the stator teeth root of vernier PM machines with different pole ratio, while all of FEA models as shown in Fig. 8(a) have the same structure parameter except for tooth width ratio, and this is also true for Fig.8 (b). As analyzing in the preceding section, the working harmonic of flux density of 11-pole ratio vernier PM machines model shown in the Fig. 8(a) consists of the harmonics with 2 pole pair, 22 pole pairs and 23 pole pairs, while the flux density harmonic with 26 poles contributes to the THD of EMF waveform, as shown in Fig.8 (a). For vernier machine with 17 pole ratio, the harmonics with 1 pole pairs, 17 pole pairs and 35 pole pairs is the working flux density distribution harmonics, while 19-pole pairs and 37-pole pairs flux density harmonics contribute to EMF harmonics as shown in Fig.8(b).

TABLE 1. Key Data of FEA Models

\begin{tabular}{|l|r|r|r|}
\hline & ModelI & ModelII & ModelIII \\
\hline Phase & 3 & 3 & 3 \\
\hline Number of pole & $20 / 4$ & $44 / 4$ & $34 / 2$ \\
\hline Pole ratio & 5 & 11 & 17 \\
\hline Number of slot & 12 & 24 & 18 \\
\hline Coil pitch & $3 / 3$ & $6 / 6$ & $9 / 9$ \\
\hline Slot per pole per phase & 1 & 2 & 3 \\
\hline Tooth ratio & 0.5 & 0.5 & 0.5 \\
\hline \hline & & ModelV & Model VI \\
\hline Phase & 3 & 3 & 3 \\
\hline Number of pole & $20 / 4$ & $20 / 4$ & 4 \\
\hline Pole ratio & 5 & 5 & - \\
\hline Number of slot & 12 & 12 & 24 \\
\hline Coil pitch & $3 / 3$ & $3 / 3$ & $5 / 6$ \\
\hline Slot per pole per phase & 1 & 1 & 2 \\
\hline Tooth ratio & 0.3 & 0.4 & 0.5 \\
\hline \hline & & ModelVIII & \\
\hline Phase & 3 & 3 & \\
\hline Number of pole & 8 & 10 & \\
\hline Pole ratio & - & - & \\
\hline Number of slot & 9 & 12 & \\
\hline Coil pitch & $8 / 9$ & $5 / 6$ & \\
\hline Slot per pole per phase & $3 / 8$ & $2 / 5$ & \\
\hline Tooth ratio & 0.5 & 0.5 & \\
\hline & & & \\
\hline & ModelVII & & \\
\hline
\end{tabular}
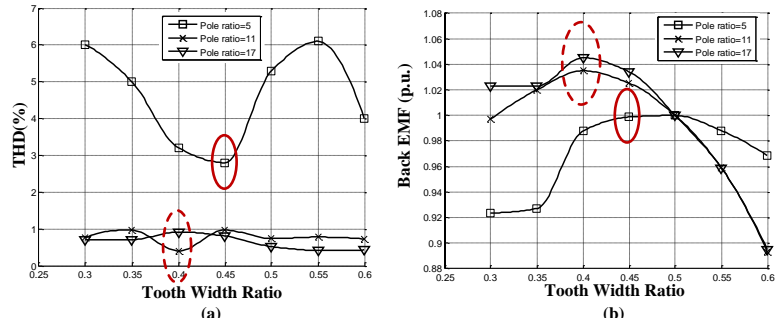

Fig. 7. The FEA results of back EMF waveform THD of vernier PM machines with different tooth width ratio

EMF Harmonics Comparison between Vernier PM Machines and Traditional PM Machines [11] shows the 12-slot 10-pole PM machine and the 9-slot 10-pole PM machine have sinusoidal EMF waveform. The FSCW PM machines can be equivalent to integer-slot PM machines from the point of star of slot view. Moreover, for the PM machine with FSCW, the first order slot harmonic $6 q \pm 1$ is not an integer number or odd number, and MMF excited by $\mathrm{PM}$ on rotor have only odd number, so the number of the order of slot harmonics of PM machines with FSCW is larger than PM machines with intergeral windings .
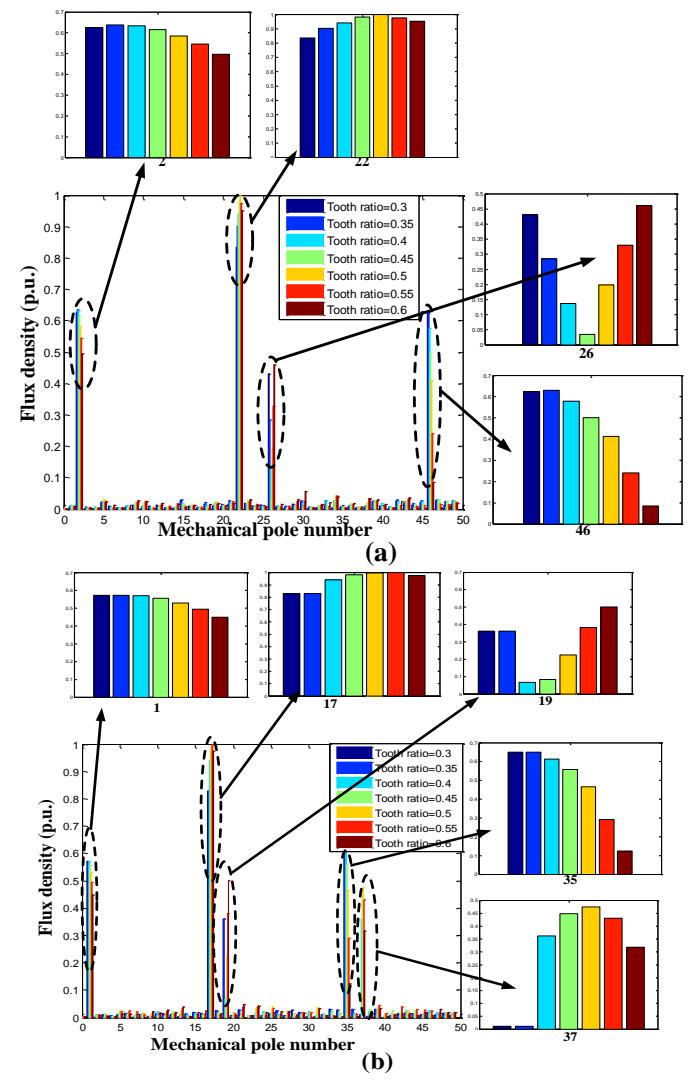

Fig. 8. FEA results of flux density distribution in the face of between stator teeth and stator yoke, (a) 11-pole-ratio vernier PM machine with 44 rotor poles, 4 stator poles, and 24 slots (b) 17-pole-ratio vernier PM machine with 34 rotor poles, 2 stator poles, and 18 slots 

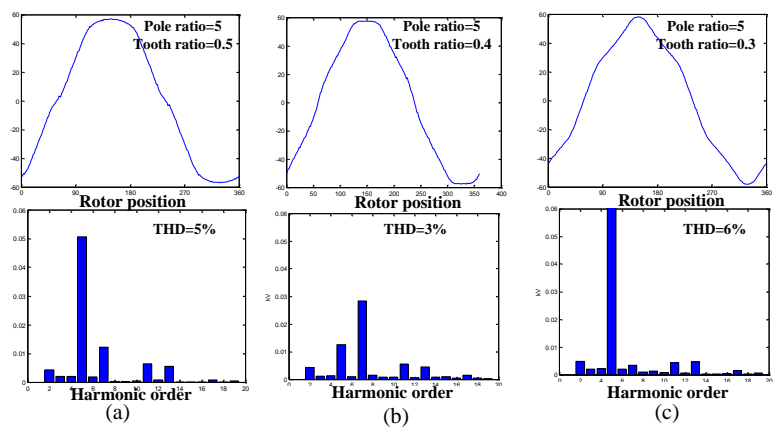

(c)

Fig. 9. Variation of EMF harmonics of vernier PM machine with tooth width ratio,(a) tooth width ratio $=0.5$,(b) tooth width ratio $=0.4$,(c) tooth width ratio $=0.3$

It should be noticed that in some case, despite that the number of the lowest slot harmonics order of the PM machine with integeral windings is equal to that of the lowest slot harmonics order of PM machines with FSCW, the EMF waveform of PM machines with FSCW is still more sinusoidal. This phenomenon can be explained by the EMF expression represented in this paper, e.g. the lowest order slot harmonics of both the 9-slots 8-poles PM machine and the 36-slots 4-poles PM machine are $E_{17}$ and $E_{19}$, however, the $E_{17}$ and $E_{19}$ of 9-slots 8-poles PM machine are determined by the slotting component $E_{\text {slotting-17,8 }}$ and $E_{\text {slotting-19,8 }}$ respectively, while the $E_{17}$ and $E_{19}$ of 36-slots 4-poles PM machine are determined by the slotting component $E_{\text {slotting-17,1 }}$ and $E_{\text {slotting-19,1 }}$ respectively, so the EMF waveform of PM machines with FSCW is more sinusoidal, as shown in Fig. 10, while this result is coincide with that the line EMF waveform is sinusoidal as shown in [11]. Fig. 9 and Fig. 10 gives several FEA results to show the comparison among back EMF waveform of different topologies.

In the forgoing analysis, the sinusoidal EMF waveform of FSCW PM machine mainly attribute to the three reasons: (1) the FSCW configuration has remarkable distributional effect on both EMF and MMF harmonics; (2) the number of slot harmonics order is large, while the amplitude of sot harmonics is determined by the $E_{\text {slotting-i,i }}$, rather than $E_{\text {slotting-i,1 }}$ in $\mathrm{PM}$ machine with integer-winding configuration;(3) The number of rotor poles and stator teeth are close, so the flux leakage excited by PM is really large, which always leads to sinusoidal EMF waveform.

Compared to a PM machine with FSCW, the slotting component of working EMF harmonic of vernier PM machines should be taken care of.The sinusoidal EMF waveform of vernier PM machines is benefited from the four reasons:

The working EMF harmonic is mainly determined by the slotting component $E_{\text {slotting }-1,1}$. Moreover, the amplitude of the slotting component $E_{\text {slotting-1,1 }}$ is much larger than that of a slot-less component of a working EMF harmonic, and the two components are in phase;

The amplitude of slotting component $E_{\text {slotting- } i}$ and slotless component $E_{\text {slotless }-i}$ of $i$ order EMF harmonic are close, while all of them are much smaller than that of working harmonic, while the slotting component

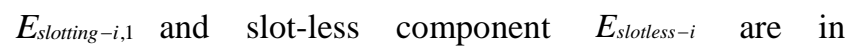
opposition. If $k \neq i, E_{\text {slotting-i,k }}$ and $E_{\text {slotting-i,k-2 }}$ are in opposition, so $E i / E_{1}$ of a vernier machines is quite small, as shown in Fig.5 and Fig. 8.

The number of rotor pole pairs and stator teeth are close, so the flux leakage excited by PM is really large, which always leads to sinusoidal EMF waveform, and this is the general characteristic of high-pole PM machines.
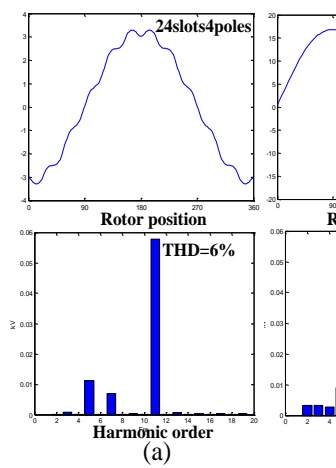
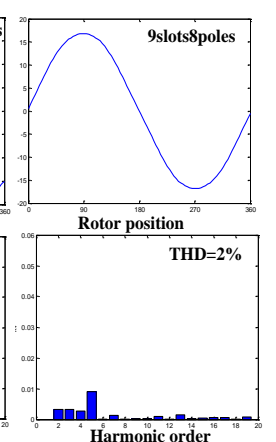

(b)

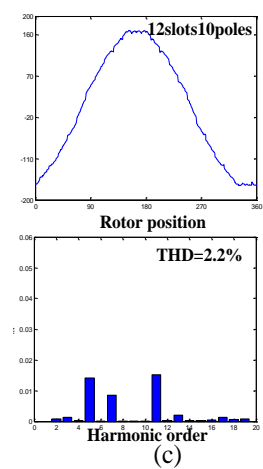

Fig. 10. FEA result of EMF harmonics of PM machines, (a) 24-slot 4-pole with 5/6 short- pitch and distributed winding; (b) 9-slot 8-pole; (c) 12-slot 10-pole

\section{Conclusion}

In this paper, an analytical expression of EMF harmonics is developed to analyze EMF harmonics of PM machines including vernier PM machines. The expression and several FEA models are employed to analyze back EMF waveform and it is verified by the FEA result, which shows that EMF waveform of vernier PM machines is inherently sinusoidal.

Moreover, this paper presents optimizing design on the pole ratio and tooth width ratio. The calculation results show that the THD of EMF waveform of vernier PM machines is much lower than that of regular PM machines with short pitch, distributed winding. Further, the vernier machines with 11 pole ratio and 17 pole ratio have more sinusoidal EMF waveform than that of vernier PM machines with 5pole ratio. The FEA results show that for 11-pole ratio 17-pole ratio vernier PM machines, the 0.4 tooth width ratio is optimized, while 0.45 -tooth width ratio is preferred for vernier machine with 5pole ratio. 
Finally, the reasons why vernier machines and PM machines with FSCW have sinusoidal EMF waveform were analyzed using the analytical EMF expression.

\section{References}

[1] Mukherji, K.C., and Tustin. A, "Vernier reluctance motor," IEE Proceeding, vol.121, no.9, pp.965-974, 1974

[2] Akio Toba, and Thomas A. Lipo, "Generic TorqueMaximizing Design Methodology of Surface PermanentMagnet Vernier PM machine," IEEE Transaction on Industry Applications, vol. 36, no. 6, pp.1539-1540, 2000

[3] Ronghai Qu, Dawei Li, and Jin Wang, "Relationship between Magnetic Gears and Vernier PM machines," IEEE International Electric Machines and Systems (ICEMs), 2011

[4] Linni Jian, Guoqing $\mathrm{Xu}$, Chunting Chris Mi,and K. T. Chau,"Analytical Method for Magnetic Field Calculation in a Low-Speed Permanent-Magnet Harmonic Machine," IEEE Transaction on Energy conversion, vol. 26, no.3, pp.826-870, 2011

[5] Guo Wei, Zhang Chengning "Design and Control of a High Torque Density and High Field-weakening Performance Permanent Magnet Vernier PM machine," IEEE International Electric Machines and Systems (ICEMs), 2011

[6] Akio Toba, and Thomas A. Lipo, "Novel Dual-Excitation Permanent Magnet Vernier PM machine," Thirty-Fourth IAS Annual conference, 1999

[7] Jiangui Li, K. T. Chau, and J. Z. Jiang, "A New Efficient Permanent-Magnet Vernier PM machine for Wind Power Generation," IEEE Transaction on Magnetic, pp.1475-1478, 2010

[8] Shuangxia Niu ,S.L.Ho ,W.N.Fu , and L. L. Wang, "Quantitative Comparison of Novel Vernier Permanent Magnet Machines," IEEE Transaction on Magnetics, vol. 46, no. 6, pp.2032-2035, June 2010

[9] T. M. Jahns and W. L. Soong, "Pulsating torque minimization techniques for permanent magnetAC motor drives-a review," IEEE Trans. Ind. Elec., vol. 43, no. 2, pp. 321-330, Apr. 1996.

[10] Seok-Hee Han, Thomas M. Jahns, and Wen L. Soong "Torque Ripple Reduction in Interior Permanent Magnet Synchronous Machines Using the Principle of Mutual Harmonics Exclusion," Forty-second IAS Annual conference, , pp.558-565, 2007

[11] D. W. Novotny and T. A. Lipo, Vector Control and Dynamics of AC Drives, Clarendo Press-Oxford, 1996.

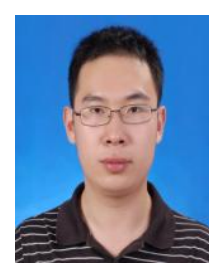

Dawei Li received the B.Eng. degrees in electrical engineering from Harbin Institute of Technology, Harbin, China,in 2010. He is currently working toward the Ph.D. degree in the School of Electrical and Electronic Engineering, from Huazhong University of Science and Technology, Wuhan, China. His research interests include design and analysis of novel permanent-magnet brushless machines.

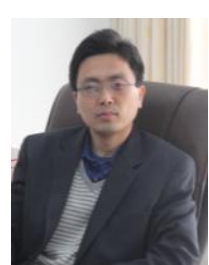

Ronghai Qu received the B.E.E. and M.S.E.E. degrees from Tsinghua University, Beijing, China, in 1993 and 1996, respectively, and the Ph.D. degree in electrical engineering from the University of Wisconsin-Madison, in 2002. From 1996 to 1998 , he was a Faculty Memberof the Electrical Engineering Department, Tsinghua University. In 1998, he joined the Wisconsin Electric Machines and Power Electronics Consortiums as Research Assistant. He became a Senior Electrical Engineer with Northland, a Scott Fetzer Company in 2002. Since 2003, he had been with the General Electric (GE) Global Research Center, Niskayuna, NY as a Senior Electrical Engineer with the Electrical Machines and Drives Laboratory. $\mathrm{He}$ has authored over 50 published technical papers and is the holder of 40+ patents/patent applications. From 2010 till now, he is the "Thousands of people plan" professor in Huazhong University of science and technology. His research and interest areas focus on advanced electrical machines and drives including megawatt direct drive permanent magnet wind generators, electric vehicles, subsea motors etc. 